\title{
Avaliando os efeitos da introdução de computadores em escolas públicas brasileiras*
}

\section{Sergio Firpo**}

Escola de Economia de São Paulo (FGV-SP) e pesquisador do C-Micro, Brasil

\section{Renan Gomes De Pieri**}

Escola de Economia de São Paulo (FGV-SP) e pesquisador do C-Micro, Brasil

\section{RESUMO}

O presente artigo tem como objetivo analisar os efeitos do uso de computadores e outras tecnologias de informação e comunicação nas escolas. Para isso, avalia-se a primeira etapa de um programa que distribuiu computadores e outros acessórios de informática e treinou professores de escolas pertencentes a municípios com baixo IDH. Estimou-se o impacto do programa sobre variáveis de desempenho dos alunos e variáveis de recursos nas escolas. Como resultado, observa-se que, a despeito do aumento significativo do acesso aos laboratórios de informática e ciência pelas escolas participantes, o impacto do programa no curto prazo tende a ser negativo sobre o desempenho dos alunos da $4^{\mathrm{a}}$ e $8^{\mathrm{a}}$ séries do ensino fundamental. Contudo, para alunos da $4^{\mathrm{a}}$ série, esse resultado negativo fica menor em termos absolutos

* Os resultados apresentados neste estudo são de inteira e exclusiva responsabilidade dos autores.

** Os autores agradecem o encorajamento e o suporte do Instituto OI Futuro para a elaboração deste estudo, a valiosa ajuda dos assistentes de pesquisa Breno Braga, João Santoro e Maraysa Ribeiro, os comentários dos participantes do Simpósio Internacional de Fronteiras de Avaliação e dos pareceristas da RBI. 
ao longo do tempo, indicando que parece haver um efeito de longo prazo positivo, porém pequeno, entre crianças mais novas e expostas às novas tecnologias de informação. Tal resultado não é encontrado para a $8^{\mathrm{a}}$ série, onde foram verificados resultados de longo prazo nulos ou negativos, indicando que crianças mais velhas, quando expostas a tecnologias de informação nas escolas, não apresentam ganhos de aprendizado.

PAlaVRAS-CHAVE | Aprendizado com computadores; Política educacional; Educação.

Códigos JEL | I21, I28, O15.

\title{
Evaluating the effects of introduction of computers in Brazilian public schools
}

\begin{abstract}
This paper analyzes the effects of using computers and other information and communication technologies in schools. For this, we evaluate the first stage of a program that distributed computers and other computer accessories and trained teachers from schools belonging to municipalities with low HDI. We estimate the program's impact on student performance variables and school resources variables. As a result, we find that despite the significant increase in access to computer and science labs by participant schools, the program's impact in the short term is negative on performance of students of grades 4th and 8th. However, for students in 4th grade, this negative result is smaller over time, indicating that there seems to be a long term positive effect, although small, between younger children and exposed to new information technologies. This result is not found for the 8th grade, where we find longterm outcomes null or negative, indicating that older children, when exposed to information technology in schools, do not exhibit learning gains.
\end{abstract}

KEYWORDS | Computer assisted learning; Educational policy; Education.

JEL Codes | I21, I28, O15. 


\section{Introdução}

O problema de acesso à educação fundamental no Brasil parece ter sido resolvido nos últimos anos, posto que em torno de $97 \%$ das crianças em idade escolar estão matriculadas nas escolas, conforme dados recentes da Pesquisa Nacional por Amostras de Domicílio (IBGE). No entanto, se a questão da frequência pode ter sido resolvida, o problema da baixa qualidade do ensino ainda parece longe de sê-lo.

Segundo resultados do Programa Internacional de Avaliação de Alunos (PISA) de 2009, o Brasil obteve a $57^{\text {a }}$ posição no ranking de matemática e a $53^{\text {a }}$ no de leitura entre 65 países. Mais do que esse pobre resultado relativo, a avaliação constatou que 49,6\% dos alunos brasileiros participantes não atingiram sequer o nível de leitura considerado básico (OCDE, 2010).

A baixa qualidade da educação no Brasil é um fator frequentemente apontado como um fundamental empecilho na solução de problemas econômicos e sociais existentes no país, como altos índices de pobreza e desigualdade de renda. Em um survey comparando países, Hanushek e Kimko (2000) concluem que é mais importante para o crescimento econômico a qualidade do que a quantidade de educação. No caso brasileiro, Curi e Menezes-Filho (2009) mostram evidencias de que a remuneração no mercado de trabalho depende mais da qualidade do que da quantidade de educação.

$\mathrm{Na}$ tentativa de melhorar a qualidade dos insumos educacionais e, consequentemente, o desempenho de alunos brasileiros em exames de proficiência padronizados, uma ideia correntemente mencionada é de aumentar o acesso dos alunos às tecnologias de informação e comunicação, como o computador e acesso à internet. Integrar informática ao processo de aprendizado tradicional em um país emergente compensaria, de certa forma, o baixo preparo dos professores e tornaria a escola mais atrativa aos alunos (LINDEN et al., 2003).

Entretanto, a literatura que avalia o impacto de computadores nas escolas não é consensual sobre a existência de efeito positivo. Rouse e Krueger (2004) avaliaram o Fast ForWord, programa norte-americano cujo tratamento fora aleatorizado e consistiu no treinamento de uso de computadores com o objetivo de melhorar as habilidades de linguagem e leitura dos alunos. Os autores concluem que o programa não tem impacto sobre linguagem e leitura, apesar de observarem certa melhora em algumas habilidades de linguagem específicas. Ainda para os EUA, Wenglinsky (1998) encontrou correlação positiva entre o número de computadores nas aulas de matemática e o desempenho dos alunos na mesma disciplina. 
Já Kozma et al. (2004) examinaram o programa World Links, que proveu escolas em países desenvolvidos com computadores interligados e treinou professores. Os resultados mostraram que os estudantes tratados tornaram-se mais hábeis no uso de tecnologias e comunicação e os professores conseguiram utilizar melhor as tecnologias nas aulas.

Para os países em desenvolvimento, as evidências também são inconclusivas. Angrist e Lavy (2002) avaliaram o impacto do uso de computadores no auxílio ao ensino de escolas israelenses. Não só não acharam impacto nos exames de matemática e de hebreu, como também observaram efeito negativo do uso de computadores. Linden et al. (2003) argumentam que tal evidência não deve influenciar os países em desenvolvimento a abandonarem o uso de computadores nas escolas pois o caso de Israel seria bem específico, uma vez que os alunos tratados pelo programa passaram a ter menos tempo do ensino tradicional do que o que se tem em escolas bem equipadas e com professores bem treinados.

Linden et al. (2003) avaliam ainda um experimento aleatorizado em Vadodara, na Índia, após um ano da implementação de programaque consistiu em submeter alunos à prática de jogos educacionais que reforçavam competências relacionadas ao ensino de matemática. Os resultados mostraram que, na média, os alunos tratados tiveram aumento de 0,37 desvios padrão na proficiência em matemática. Em outro experimento aleatório na Índia, Linden (2008) conclui que se o uso da informática no auxílio ao aprendizado se der de forma complementar ao ensino tradicional o impacto sobre proficiência é positivo; todavia, caso tal uso substitua em certa parte o ensino tradicional, o impacto pode ser negativo.

$\mathrm{Na}$ Colômbia, Barrera e Linden (2009) avaliaram o programa Computadores para Educar e observaram que o programa teve pouco impacto sobre o desempenho dos alunos em exames de proficiência.

Para o Brasil Neri, Moura e Correa (2011) calcularam medidas de correlações brutas e parciais entre o fato de a criança possuir acesso ao computador e internet e desempenho no Saeb. Os resultados são positivos, muito embora não representam explicitamente causalidade. Kist et al. (2007) analisou o programa "Um computador por aluno" em uma escola de Porto Alegre e argumenta que o acesso ao computador pode melhor a capacidade de escrita dos alunos.

Entretanto, Dwyer et al. (2007) comparou, usando dados do SAEB, alunos que tinham acesso a computador com quem não tinha e evidenciou que o uso de computadores diminuiu a proficiência em português e matemática. 
De forma geral, a literatura mostra que o simples acréscimo de computadores e outros equipamentos de informática traz pouco impacto sobre o desempenho dos alunos ou até mesmo impacto negativo. Outra consideração relevante é a de que as tecnologias de informação devem atuar de modo complementar ao ensino e não substituir totalmente o método tradicional, conforme se observou nos experimentos citados em Israel e na Índia. Além disso, parece ser fundamental o treinamento dos professores para o uso da tecnologia, bem como a introdução de incentivos para que estes se dediquem a utilizar os novos equipamentos.

Este trabalho analisa os efeitos de um programa brasileiro inovador de inclusão digital que visa a melhoria dos padrões de ensino por meio da maior exposição às tecnologias de informação e comunicação. Tenta-se ainda entender quais são os possíveis canais por meio dos quais a exposição dos alunos e professores às tecnologias de informação e comunicação pode afetar qualidade do ensino.

O programa analisado é o Tonomundo, lançado em 2000, que tem como meta integrar escola, família e comunidade por meio de tecnologias em telecomunicações. ${ }^{1}$ Iniciado em pequena escala, atendendo a 68 escolas escolhidas por se localizarem em municípios com baixos valores do Índice de Desenvolvimento Humano (IDH), o projeto vem se expandindo paulatinamente e já foi implantado em mais de 500 escolas, tendo atualmente tornado-se parte de políticas públicas municipais e estaduais.

Além de equipar as escolas integrantes com laboratórios de informática compostos por computadores, scanners, impressoras e acesso à Internet, o Tonomundo também promove um programa de formação que dá suporte aos educadores no desenvolvimento de projetos que incluem a utilização pedagógica dessas ferramentas no dia-a-dia das escolas. Dessa forma, os participantes são estimulados a melhor aproveitar os equipamentos de informática e a contribuir para o atendimento das necessidades das comunidades atendidas.

No programa ainda é cultivada a ideia de criar uma comunidade virtual de professores, alunos e demais envolvidos por meio de fóruns virtuais. A organização do programa também divulga em seu sítio na Internet nomes e fotos de escolas e professores que se destacam.

No presente trabalho, avalia-se o impacto do projeto sobre as escolas que ingressaram até 2004. Tal regra deriva do interesse em estimar o impacto do programa sobre proficiência, que passa a ser medida pela Prova Brasil em 2005. Das 402 escolas tratadas na amostra, menos de 70 delas, aquelas do projeto-piloto,

1 O programa foi concebido como fruto da parceria entre o Instituto Oi Futuro e a Escola do Futuro da USP. Informações detalhadas podem ser obtidas no sítio do programa na Internet: http://www.tonomundo.org.br/. 
ingressaram entre 2000 e 2001. O restante pertence ao estado de Pernambuco e ingressaram no programa em 2004.

O interesse recai sobre (i) medidas de desempenho dos alunos, como proficiência na Prova Brasil e taxas de aprovação, (ii) variáveis que medem a qualidade dos insumos escolares como a escolaridade dos professores e (iii) medidas de atendimento das necessidades das comunidades onde se localizam as escolas, como a estrutura física da escola e do seu entorno.

$\mathrm{O}$ artigo está dividido em mais quatro seçôes. Na próxima, descreve-se a base de dados. Posteriormente, apresentam-se a metodologia de avaliação do programa, as estatísticas descritivas, os resultados encontrados e, finalmente, as conclusões.

\section{Base de dados}

Neste trabalho são utilizadas três bases de dados. A primeira corresponde aos Censos Escolares de 1999 e 2006 do Ministério da Educação, . que trazem informações diversas sobre todas as escolas brasileiras públicas e privadas. Estamos especialmente interessados nos dados sobre a disponibilidade e utilização de recursos de informática, desempenho dos alunos, escolaridade dos professores, condições das escolas públicas e do seu entorno.

A segunda base de dados empregada é o Censo Demográfico de 2000, do Instituto Brasileiro de Geografia e Estatística (IBGE). A partir do Censo foram extraídas informações sobre o IDH dos municípios. Essa referência servirá para utilizar o seguinte grupo de controle: escolas em municípios não beneficiados pelo programa, mas com características similares daqueles beneficiados.

A terceira base de dados contém informações do Inep sobre o desempenho das escolas em uma série de medidas como taxa de aprovação, Ideb, proficiência em português e matemática na Prova Brasil e a nota média na Prova Brasil. Obteve-se informação para os anos de 2005 e 2007 a fim de analisar o impacto do programa em diferentes períodos de tempo.

Do Censo Escolar foram coletadas as seguintes variáveis de resposta em relação ao ensino fundamental: escolaridade média dos professores, existência de laboratório e estrutura do entorno da escola. Esta última consiste em uma variável dummy que assume valor 1 se a escola tem acesso às redes públicas de esgoto, água e luz, e zero, caso contrário.

Também do Censo Escolar, obtiveram-se a variável dummy indicando se a escola tem acesso à Internet e o número de computadores por aluno do Ensino 
Fundamental. Além disso, extraíram-se variáveis de controle que dão dimensão do tamanho da escola, como número de salas, de professores e de turmas do ensino fundamental. A variável que indica tratamento foi construída a partir da relação das escolas tratadas disponível no sitio do programa na internet no começo de $2008 .^{2}$

\section{Metodologia}

Caso as escolas participantes do programa tivessem sido escolhidas de maneira aleatória, uma simples diferença de médias das variáveis de resposta entre o grupo de escolas tratadas e não-tratadas seria uma estimativa sem viés do efeito causal do programa.

No entanto, elas foram selecionadas conforme critérios preestabelecidos, em municípios com baixo IDH. Assim, a forma como se lidou aqui com essa seleção foi gerar um grupo de controle a partir do grupo de escolas com características semelhantes às escolas tratadas, exceto pelo fato de não terem participado do programa. No caso particular deste estudo, definiu-se o grupo de controle da seguinte forma: utilizando as informaçôes do Censo Populacional de 2000, para cada município onde havia escolas participantes do programa, foram escolhidos dois outros municípios semelhantes em termos de IDH e na mesma Unidade da Federação (UF). O grupo de controle corresponderá a todas as escolas públicas dos municípios semelhantes, acrescentado das escolas públicas dos próprios municípios onde houve escolas tratadas, mas que não foram incluídas inicialmente no programa.

Tal mecanismo corresponde a um matching onde a probabilidade de ser tratado é explicada pela UF da escola e pelo IDH do município. Na hipótese de que, condicional nessas duas variáveis, o tratamento é aleatório, uma simples diferença de médias entre tratados e controles para cada variável dependente que se quer medir corresponderia ao efeito causal médio do programa sobre as escolas públicas. Essa hipótese de identificação é comumente chamada pela literatura de avaliação de impacto de hipótese de seleção em observáveis.

Entretanto, a fim de se evitar o viés de seleção que pode existir caso a hipótese de seleção em observáveis não valha, estima-se, quando possível, o impacto do programa de uma forma alternativa e robusta à violação dessa hipótese. Utilizou-se o estimador de diferenças em diferenças para avaliar o efeito sobre alguns insumos escolares como escolaridade média dos professores, existência de laboratório e infraestrutura física. O método de diferenças em diferenças produz estimativas consistentes

2 Uma lista das escolas tratadas com os códigos do Censo Escolar, ano de entrada no programa e tipo de dependência administrativa (estadual, municipal) está disponível sob pedido. 
para o efeito causal do programa desde que a evolução temporal das características não-observáveis seja a mesma entre os grupos de controle e tratamento.

Contudo, para se poder utilizar o método de diferenças em diferenças é necessário obter dados dos grupos de controle e tratamento antes e depois do programa. No caso da avaliação do impacto do programa sobre proficiência isso não é possível, posto que medidas de desempenho escolar passaram a ser calculadas para todas as escolas públicas apenas a partir de 2005. Nesse caso, o presente estudo baseou-se na análise em métodos que requerem a hipótese de seleção em observáveis.

\subsection{Impacto sobre recursos escolares}

Analisou-se o efeito do programa sobre escolaridade média dos professores, existência de laboratório e estrutura do entorno da escola. A escolha dessa última variável vem de o programa, ao inserir novos equipamentos e uma dinâmica diferente e inovadora de aulas na escola, poder incentivar e motivar os alunos e a comunidade envolvida a pleitear melhorias para a comunidade junto aos órgãos competentes. No caso específico da variável que mede a escolaridade média dos professores, uma escola com melhores equipamentos de trabalho pode servir como atrativo de melhores professores.

A estratégia de identificação do efeito causal baseia-se na hipótese de que, na ausência do programa, escolas dos grupos de controle e tratamento evoluiriam de formas similares. Assim, qualquer diferença entre esses grupos na evolução temporal se dá especificamente pelo impacto do programa (ANGRIST; PISCHKE, 2008). Sob tal hipótese, uma estimativa desse efeito causal é facilmente obtida pelo método de diferenças em diferenças. A especificação da forma funcional usada nas estimações se dá a seguir:

$$
Y_{i m t}=\alpha+\beta D_{i}+\gamma T_{t}+\delta D_{i} T_{t}+\theta_{1} T_{t} X_{i m t}^{\theta}+\theta_{2} T_{t} X_{m}+\theta_{3} X_{i m t}^{\theta}+\theta_{4} X_{m}+
$$

onde

- $i$ identifica a escola, $m$ o município e $t$ o tempo.

$-Y$ é a variável de resposta

- $D=1$ se escola participa do programa, 0 caso contrário

- $T=1$ se ano for igual a 2006, 0 caso seja 2000

- $X^{e}$ é o vetor de características das escolas: número de salas de aula, número 
de professores do ensino fundamental, número de turmas no E. F., variável dummy informando se tem acesso à Internet e número de computadores por aluno do E. F.

$X_{m}$ é o vetor de características do município (IDH em 2000 e UF) usado para escolha das variáveis do grupo de controle.

- $u$ é o fator não observável que afeta $Y$. Supõe-se que esse fator tem média zero condicional nas outras variáveis.

O parâmetro $\delta$ captura o efeito total do programa controlando para as demais variáveis que poderiam afetar $Y$. Define-se tal parâmetro como:

$$
\begin{aligned}
& \delta=\left[E\left(Y_{i} \mid D_{i}=1, T=1, X^{e}, X_{m}\right)-E\left(Y_{i} \mid D_{i}=0, T=1, X^{e}, X_{m}\right)\right] \\
& -\left[E\left(Y_{i} \mid D_{i}=1, T=0, X^{e}, X_{m}\right)-E\left(Y_{i} \mid D_{i}=0, T=0, X^{e}, X_{m}\right)\right]
\end{aligned}
$$

\subsection{Impacto sobre desempenho dos alunos}

Para as variáveis de desempenho dos alunos e mais especificamente para os exames de proficiência, não há informações anteriores a 2005, o que impossibilita a utilização do estimador de diferenças em diferenças. Para esses casos, aplicam-se três estimadores que se baseiam na hipótese de seleção em observáveis para evitar o viés de seleção: regressão usando o método dos mínimos quadrados ordinários (MQO), onde se regride a variável dependente contra a dummy de tratamento e o vetor de características das escolas e municípios mencionados na seção anterior. A equação 3 representa a estimação:

$Y_{i m}=\alpha+\beta D_{i}+\theta_{1} X_{i m}^{e}+\theta_{2} X_{m}+u_{i m}$

$\mathrm{O}$ segundo método é a regressão por $\mathrm{MQO}$, com a diferença que neste exercício interage-se a dummy de tratamento com a razão número de computadores por aluno e acesso à Internet com o intuito de captar os diferentes impactos que cada elemento do programa possa ter. A equação 4 representa tal forma funcional:

$$
\beta_{1} W_{i} D_{i}+\theta_{1} X_{i m}^{*}+\theta_{2} X_{m}+u_{i m}
$$

onde $W$ representa as variáveis número de computadores por aluno e acesso à Internet. O parâmetro $\beta_{1}$ representa o impacto do programa pelo canal das variáveis do vetor $W$. 
O terceiro método é a regressão por $\mathrm{MQO}$, mas ao invés de controlar por um vetor de covariadas, estima-se em um primeiro estágio uma regressão logística da probabilidade de receber o tratamento sobre o vetor das covariadas (propensity score) e depois imputa-se tal propensity score como variável independente no MQO juntamente da dummy de tratamento. Em todos os casos, o coeficiente que acompanha a dummy de tratamento captura o efeito causal do programa. A equação 5 apresenta a forma funcional do propensity score e a equação 6 o MQO estimado:

$\operatorname{Prob}\left(D=1 \mid X^{\varepsilon}, X_{\text {im }}\right)=\Lambda\left(X^{\varepsilon}, X_{\text {im }}\right)$

onde $\Lambda$ é a distribuição logística acumulada. Assim, temos que

$Y_{i m}=\alpha+\beta D_{i}+\beta_{1} \Lambda\left(X^{\varepsilon}, X_{i m}\right)+u_{i m}$

\section{Resultados}

Apresentam-se os resultados para estimação do impacto do programa sobre dois conjuntos de variáveis: variáveis de desempenho dos alunos, como taxa de aprovação, proficiência em português e matemática na Prova Brasil e Ideb; e variáveis de recursos escolares, como a infraestrutura da escola, existência de laboratório de informática ou ciências e escolaridade média dos professores.

\subsection{Estatísticas Descritivas}

$\mathrm{Na}$ Tabela 1, apresentam-se tanto para o grupo dos tratados como dos controles as estatísticas descritivas das variáveis que compõem o vetor de recursos das escolas para os anos de 1999 e 2006., Observa-se que, nestes dois anos, a quantidade média de recursos nas escolas tratadas é maior do que a das escolas do grupo de controle. A diferença mais latente parece ser no número de alunos, número de computadores, acesso à Internet, existência de laboratório e a variável dummy de infraestrutura, sobretudo aquela que indica escolas que têm acesso ao fornecimento de água, energia elétrica e esgoto.

As diferenças pré-tratamento entre os dois grupos mostram que, embora as escolas tratadas e controles sejam do mesmo estado e tenham IDH parecido, elas apresentam algumas desigualdades que fazem com que a simples divergência de médias entre os desempenhos dos dois grupos possa acarretar em viés de seleção. 
Tabela 1

Estatísticas descritivas - Escolas tratadas e grupo de controle 1999 e 2006

\begin{tabular}{|c|c|c|c|c|c|}
\hline & \multicolumn{2}{|c|}{1999} & \multicolumn{2}{|c|}{2006} \\
\hline & & Controle & Tratamento & Controle & Tratamento \\
\hline \multirow{3}{*}{$\begin{array}{l}N^{\circ} \text { de alunos no } \\
\text { ensino fundamental }\end{array}$} & Média & 186.143 & 699.289 & 163.341 & 509.450 \\
\hline & Desv. Padrão & 306.386 & 424.882 & 278.608 & 344.790 \\
\hline & Obs & 18674 & 402 & 18675 & 402 \\
\hline \multirow{3}{*}{$\begin{array}{l}\text { Escolaridade média } \\
\text { dos professores }\end{array}$} & Média & 11.464 & 12.949 & 11.847 & 13.170 \\
\hline & Desv. Padrão & 2.269 & 0.557 & 1.467 & 0.849 \\
\hline & Obs & 15632 & 340 & 11861 & 364 \\
\hline \multirow{3}{*}{$\begin{array}{l}\text { Estrutura (pelo } \\
\text { menos } 1 \text { entre } \\
\text { água, luz e esgoto) }\end{array}$} & Média & 0.923 & 0.998 & 0.850 & 0.990 \\
\hline & Desv. Padrão & 0.267 & 0.050 & 0.357 & 0.099 \\
\hline & Obs & 18674 & 402 & 18675 & 402 \\
\hline \multirow{3}{*}{$\begin{array}{l}\text { Estrutura (todos } \\
\text { entre água, luz e } \\
\text { esgoto) }\end{array}$} & Média & 0.587 & 0.988 & 0.718 & 0.988 \\
\hline & Desv. Padrão & 0.492 & 0.111 & 0.450 & 0.111 \\
\hline & Obs & 18674 & 402 & 18675 & 402 \\
\hline \multirow{3}{*}{ Internet } & Média & 0.009 & 0.027 & 0.749 & 0.935 \\
\hline & Desv. Padrão & 0.093 & 0.163 & 0.434 & 0.246 \\
\hline & Obs & 18674 & 402 & 18675 & 402 \\
\hline \multirow{3}{*}{$\begin{array}{l}\text { Laboratório (ciências } \\
\text { ou informática) }\end{array}$} & Média & 0.050 & 0.159 & 0.098 & 0.950 \\
\hline & Desv. Padrão & 0.218 & 0.366 & 0.298 & 0.218 \\
\hline & Obs & 18674 & 402 & 18675 & 402 \\
\hline \multirow{3}{*}{$N^{\circ}$ de computadores } & Média & 0.451 & 0.769 & 1.568 & 11.219 \\
\hline & Desv. Padrão & 5.440 & 3.592 & 11.498 & 5.920 \\
\hline & Obs & 18674 & 402 & 18675 & 402 \\
\hline \multirow{3}{*}{$N^{\circ}$ de professores } & Média & 6.981 & 13.244 & 6.080 & 23.632 \\
\hline & Desv. Padrão & 9.512 & 9.762 & 10.840 & 15.073 \\
\hline & Obs & 18674 & 402 & 18675 & 402 \\
\hline \multirow{3}{*}{$N^{\circ}$ de salas de aula } & Média & 4.431 & 10.970 & 4.808 & 11.592 \\
\hline & Desv. Padrão & 5.614 & 5.941 & 6.024 & 6.182 \\
\hline & Obs & 18674 & 402 & 18675 & 402 \\
\hline \multirow{3}{*}{$N^{\circ}$ de turmas } & Média & 5.311 & 18.930 & 5.076 & 14.567 \\
\hline & Desv. Padrão & 9.086 & 10.195 & 8.658 & 9.127 \\
\hline & Obs & 18674 & 402 & 18675 & 402 \\
\hline \multirow{3}{*}{$\begin{array}{l}N^{\circ} \text { comput. / alunos } \\
\text { ens. fundamental }\end{array}$} & Média & 0.0007 & 0.0012 & 0.0041 & 0.0295 \\
\hline & Desv. Padrão & 0.0042 & 0.0068 & 0.0152 & 0.0286 \\
\hline & Obs & 16332 & 384 & 14247 & 381 \\
\hline
\end{tabular}

Fonte: Ministério da Educação. Censos Escolares 2000 e 2006; IBGE. Censo Demográfico 2000. 
No caso específico de algumas variáveis como a existência de melhor infraestrutura, essa diferença poderia ser esperada dado que a implementação de um programa que usa diversos aparatos tecnológicos exige que a escola tenha condições estruturais de recebê-lo.

Já quando se analisa o período pós-tratamento, em 2006, a tabela mostra que alguns insumos relacionados ao programa têm considerável aumento como a existência de laboratório de informática ou ciências e o número de computadores por aluno.

A Tabela 2 mostra as diferenças entre tratados e controles no que diz respeito ao desempenho dos alunos quanto à taxa de aprovação, proficiência na Prova Brasil e em suas provas de português e matemática e o Índice de Desenvolvimento da Educação Básica (Ideb) das escolas. ${ }^{3}$ Tais variáveis designam um subgrupo específico da população de escolas por representar apenas escolas urbanas e com um determinado número mínimo de alunos na série. ${ }^{4}$ Estima-se no trabalho o impacto do programa nesses índices nos anos de 2005 e na diferença entre 2007 e 2005, com o intuito de capturar o efeito do programa ao longo do tempo.

Tabela 2

Estatísticas descritivas das escolas da taxa de aprovação, Ideb, proficiência na Prova Brasil e nas provas de Português e Matemática 2005 e 2007

\begin{tabular}{|c|c|c|c|c|c|}
\hline & \multicolumn{2}{|c|}{ Tratados } & \multicolumn{2}{|c|}{ Controles } \\
\hline & & 2005 & 2007 & 2005 & 2007 \\
\hline \multirow{3}{*}{ 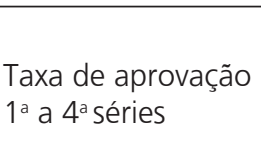 } & Média & 0.784 & 0.795 & 0.792 & 0.830 \\
\hline & Desv. Padrão & 0.105 & 0.106 & 0.121 & 0.116 \\
\hline & Obs & 181 & 228 & 3088 & 3658 \\
\hline \multirow{3}{*}{$\begin{array}{l}\text { Taxa de aprovação } \\
5^{\text {a }} \text { a } 8^{\mathrm{a}} \text { séries }\end{array}$} & Média & 0.636 & 0.651 & 0.699 & 0.745 \\
\hline & Desv. Padrão & 0.127 & 0.133 & 0.136 & 0.151 \\
\hline & Obs & 245 & 292 & 2137 & 2507 \\
\hline \multirow{3}{*}{ Ideb 4a série } & Média & 3.235 & 3.388 & 3.488 & 3.735 \\
\hline & Desv. Padrão & 0.602 & 0.675 & 0.874 & 0.884 \\
\hline & Obs & 181 & 228 & 3088 & 3658 \\
\hline
\end{tabular}

3 O Ideb é uma função da taxa de aprovação com a proficiência na Prova Brasil (INEP, 2011). O índice varia de 0 a 10.

4 Realizam a Prova Brasil todas as escolas públicas com pelo menos 10 alunos na série de interesse. As notas na Prova Brasil vão de 0 a 500 (INEP, 2011). 
Tabela 2

Estatísticas descritivas das escolas da taxa de aprovação, Ideb, proficiência na Prova Brasil e nas provas de Português e Matemática 2005 e 2007

\begin{tabular}{|c|c|c|c|c|c|}
\hline & \multicolumn{2}{|c|}{ Tratados } & \multicolumn{2}{|c|}{ Controles } \\
\hline & & 2005 & 2007 & 2005 & 2007 \\
\hline \multirow{3}{*}{ Ideb 8a série } & Média & 2.544 & 2.610 & 2.976 & 3.187 \\
\hline & Desv. Padrão & 0.666 & 0.685 & 0.789 & 0.909 \\
\hline & Obs & 245 & 292 & 2137 & 2507 \\
\hline \multirow{3}{*}{$\begin{array}{l}\text { Nota na Prova Brasil } \\
4^{\text {a }} \text { série }\end{array}$} & Média & 4.119 & 4.251 & 4.366 & 4.465 \\
\hline & Desv. Padrão & 0.426 & 0.523 & 0.641 & 0.648 \\
\hline & Obs & 181 & 228 & 3088 & 3658 \\
\hline \multirow{3}{*}{$\begin{array}{l}\text { Nota na Prova Brasil } \\
8^{\text {a }} \text { série }\end{array}$} & Média & 3.976 & 3.983 & 4.227 & 4.238 \\
\hline & Desv. Padrão & 0.419 & 0.423 & 0.560 & 0.622 \\
\hline & Obs & 245 & 292 & 2137 & 2507 \\
\hline \multirow{3}{*}{$\begin{array}{l}\text { Nota de português } \\
4^{\text {a }} \text { série }\end{array}$} & Média & 161.507 & 160.617 & 168.040 & 166.046 \\
\hline & Desv. Padrão & 12.308 & 14.129 & 17.824 & 17.395 \\
\hline & Obs & 181 & 228 & 3088 & 3658 \\
\hline \multirow{3}{*}{$\begin{array}{l}\text { Nota de português } \\
\text { 8a série }\end{array}$} & Média & 213.231 & 215.023 & 220.136 & 222.382 \\
\hline & Desv. Padrão & 12.544 & 12.955 & 16.430 & 18.860 \\
\hline & Obs & 245 & 292 & 2137 & 2507 \\
\hline \multirow{3}{*}{$\begin{array}{l}\text { Nota de } \\
\text { matemática } \\
4^{\text {a }} \text { série }\end{array}$} & Média & 168.633 & 176.390 & 175.384 & 182.461 \\
\hline & Desv. Padrão & 11.402 & 14.846 & 17.160 & 18.047 \\
\hline & Obs & 181 & 228 & 3088 & 3658 \\
\hline \multirow{3}{*}{$\begin{array}{l}\text { Nota de } \\
\text { matemática } \\
\text { 8a série }\end{array}$} & Média & 225.347 & 223.940 & 233.504 & 231.878 \\
\hline & Desv. Padrão & 13.262 & 13.430 & 17.916 & 19.399 \\
\hline & Obs & 245 & 292 & 2137 & 2507 \\
\hline
\end{tabular}

Fonte: Ministério da Educação. Censos Escolares 2000 e 2006; IBGE. Censo Demográfico 2000.

Observa-se na Tabela 2 que a diferença média entre tratados e controles favorece o último grupo, mas que em diversos critérios parece ter havido alguma melhora das escolas tratadas. Tal padrão é testado posteriormente controlando-se para variáveis observáveis (confounded variables), mas a inspeção a olho nu da Tabela 2 levanta a hipótese de que, embora o programa possa ter tido impacto negativo no curto prazo sobre o desempenho dos alunos, ele tenha começado a se dissipar à medida em que os benefícios de prazo mais longo foram maturando. 


\subsection{Resultados para variáveis de desempenho dos alunos}

A Tabela 3 mostra os efeitos do programa para a taxa de aprovação dos alunos de $1^{\text {a }}$ a $4^{\text {a }}$ séries do ensino fundamental no ano de 2005. Para essa e para as demais variáveis dessa seção foram estimadas as equações 3 a 6 da seção 3 .

Tabela 3

Impacto sobre a taxa de aprovação nas $1^{\text {a }}$ a $4^{\text {a }}$ séries 2005

\begin{tabular}{|c|c|c|c|}
\hline & MQO & $\begin{array}{l}\text { MQO com } \\
\text { interação }\end{array}$ & P-score \\
\hline \multirow{2}{*}{ Tratamento } & -0.002 & -0.003 & -0.008 \\
\hline & $(0.008)$ & $(0.008)$ & $(0.007)$ \\
\hline \multirow{2}{*}{ Tratamento ${ }^{(1)}\left(N^{\circ}\right.$ comput. / aluno E.F.) } & & 3.730 & \\
\hline & & $(4.119)$ & \\
\hline \multirow{2}{*}{ Tratamento $^{(1)}$ Internet } & & -0.141 & \\
\hline & & $(0.087)$ & \\
\hline \multirow{2}{*}{$\mathrm{N}^{\circ}$ de salas de aula } & $0.001^{(2)}$ & $0.001^{(2)}$ & \\
\hline & $(0.001)$ & $(0.001)$ & \\
\hline \multirow{2}{*}{ № de turmas no ensino fundamental } & -0.000 & -0.000 & \\
\hline & $(0.000)$ & $(0.000)$ & \\
\hline \multirow{2}{*}{ Internet } & 0.007 & 0.008 & \\
\hline & $(0.014)$ & $(0.014)$ & \\
\hline \multirow{2}{*}{$\mathrm{N}^{\circ}$ comput. / alunos ens. fundamental } & $5.915^{(3)}$ & $5.902^{(3)}$ & \\
\hline & $(0.962)$ & $(0.972)$ & \\
\hline \multirow{2}{*}{$N^{\circ}$ de professores do E. F. } & $-0.001^{(3)}$ & $-0.001^{(3)}$ & \\
\hline & $(0.000)$ & $(0.000)$ & \\
\hline \multirow{2}{*}{ Propensity score } & & & -0.007 \\
\hline & & & $(0.032)$ \\
\hline \multirow{2}{*}{ Constante } & $0.783^{(3)}$ & $0.783^{(3)}$ & $0.792^{(3)}$ \\
\hline & $(0.005)$ & $(0.005)$ & $(0.002)$ \\
\hline $\mathrm{N}$ & 3252 & 3252 & 3252 \\
\hline$R^{2}$ & 0.048 & 0.048 & 0.000 \\
\hline
\end{tabular}

Fonte: Ministério da Educação. Censos Escolares 2000 e 2006; IBGE. Censo Demográfico 2000.

(1) $\mathrm{p}<0.1$.

(2) $\mathrm{p}<0.05$.

(3) $\mathrm{p}<0.01$.

Nota: Desvios-padrões robustos em parênteses. 
Como se observa, o coeficiente da dummy de tratamento é negativo, porém estatisticamente não diferente de zero para os três estimadores. Também têm impacto zero os canais de mais quantidade de computadores e acesso à Internet. Os resultados valem para as escolas urbanas, que representam a maior parte das escolas tratadas.

A Tabela 4 mostra o impacto do programa sobre o Ideb da 4a série em 2005

Tabela 4

Impacto sobre o Ideb na $4^{\text {a }}$ série 2005

\begin{tabular}{|c|c|c|c|}
\hline & MQO & $\begin{array}{l}\text { MQO com } \\
\text { interação }\end{array}$ & P-score \\
\hline Tratamento & $\begin{array}{c}-0.191^{(2)} \\
(0.048) \\
\end{array}$ & $\begin{array}{c}-0.192^{(2)} \\
(0.049) \\
\end{array}$ & $\begin{array}{r}-0.265^{(2)} \\
(0.035) \\
\end{array}$ \\
\hline 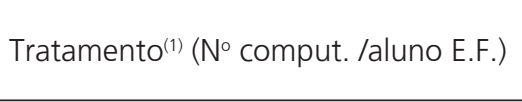 & & $\begin{array}{r}12.769 \\
(30.502)\end{array}$ & \\
\hline Tratamento ${ }^{(1)}$ Internet & & $\begin{array}{l}-0.681 \\
(0.637)\end{array}$ & \\
\hline$N^{\circ}$ de salas de aula & $\begin{array}{l}0.020^{(2)} \\
(0.004)\end{array}$ & $\begin{array}{l}0.020^{(2)} \\
(0.004)\end{array}$ & \\
\hline № de turmas no ensino fundamental & $\begin{array}{l}-0.000 \\
(0.002)\end{array}$ & $\begin{array}{r}-0.000 \\
(0.002)\end{array}$ & \\
\hline Internet & $\begin{array}{r}-0.080 \\
(0.115) \\
\end{array}$ & $\begin{array}{r}-0.075 \\
(0.116) \\
\end{array}$ & \\
\hline $\mathrm{N}^{\circ}$ comput. / alunos ens. fundamental & $\begin{array}{r}61.221^{(2)} \\
(9.063)\end{array}$ & $\begin{array}{r}61.245^{(2)} \\
(9.185)\end{array}$ & \\
\hline$N^{\circ}$ de professores do E. F. & $\begin{array}{c}-0.006^{(2)} \\
(0.002)\end{array}$ & $\begin{array}{c}-0.006^{(2)} \\
(0.002)\end{array}$ & \\
\hline Propensity score & & & $\begin{array}{r}0.367 \\
(0.235) \\
\end{array}$ \\
\hline Constante & $\begin{array}{l}3.302^{(2)} \\
(0.033)\end{array}$ & $\begin{array}{l}3.302^{(2)} \\
(0.033)\end{array}$ & $\begin{array}{l}3.473^{(2)} \\
(0.018)\end{array}$ \\
\hline $\mathrm{N}$ & 3252 & 3252 & 3252 \\
\hline $\mathrm{R}^{2}$ & 0.111 & 0.111 & 0.005 \\
\hline
\end{tabular}

Fonte: Ministério da Educação. Censos Escolares 2000 e 2006; IBGE. Censo Demográfico 2000.

(1) $\mathrm{p}<0.1$.

(2) $\mathrm{p}<0.01$.

Nota: Desvios-padrōes robustos em parênteses. 
Como se observa pelas duas primeiras colunas, o efeito do Ideb é negativo sobre a qualidade da educação, evidenciando que o fato de a escola participar do programa fez com que seu Ideb diminuísse em 0,19 pontos, em média (em uma escala de 0 a 10). Tal resultado está em conformidade com Dwyer et al. (2007), que também concluem que a inserção de computadores nas escolas pode diminuir o desempenho dos alunos. A interação do tratamento com outras variáveis não designou impacto algum.

Tabela 5

Impacto sobre o Ideb na $4^{\text {a }}$ série 2007

\begin{tabular}{|c|c|c|c|}
\hline & MQO & $\begin{array}{l}\text { MQO com } \\
\text { interação }\end{array}$ & P-score \\
\hline Tratamento & $\begin{array}{r}-0.307^{(2)} \\
(0.048)\end{array}$ & $\begin{array}{r}-0.302^{(2)} \\
(0.049)\end{array}$ & $\begin{array}{r}-0.364^{(2)} \\
(0.044)\end{array}$ \\
\hline Tratamento $^{(1)}\left(\mathrm{N}^{\circ}\right.$ comput. / aluno E.F.) & & $\begin{array}{r}6.764 \\
(34.030)\end{array}$ & \\
\hline Tratamento $^{(1)}$ Internet & & $\begin{array}{l}-0.858 \\
(0.723)\end{array}$ & \\
\hline$N^{\circ}$ de salas de aula & $\begin{array}{l}0.028^{(2)} \\
(0.004)\end{array}$ & $\begin{array}{l}0.028^{(2)} \\
(0.004)\end{array}$ & \\
\hline$N^{\circ}$ de turmas no ensino fundamental & $\begin{array}{l}-0.004 \\
(0.002)\end{array}$ & $\begin{array}{l}-0.004 \\
(0.002)\end{array}$ & \\
\hline Internet & $\begin{array}{r}0.072 \\
(0.123)\end{array}$ & $\begin{array}{r}0.090 \\
(0.123)\end{array}$ & \\
\hline $\begin{array}{l}\text { № comput. / alunos ens. } \\
\text { fundamental }\end{array}$ & $\begin{array}{r}36.495^{(2)} \\
(9.273)\end{array}$ & $\begin{array}{r}36.487^{(2)} \\
(9.374)\end{array}$ & \\
\hline$N^{\circ}$ de professores do E. F. & $\begin{array}{l}-0.005^{(2)} \\
(0.002)\end{array}$ & $\begin{array}{l}-0.005^{(2)} \\
(0.002)\end{array}$ & \\
\hline Propensity score & & & $\begin{array}{l}0.609^{(3)} \\
(0.242) \\
\end{array}$ \\
\hline Constante & $\begin{array}{l}3.547^{(2)} \\
(0.030)\end{array}$ & $\begin{array}{l}3.547^{(2)} \\
(0.030)\end{array}$ & $\begin{array}{l}3.712^{(2)} \\
(0.015)\end{array}$ \\
\hline $\mathrm{N}$ & 3852 & 3852 & 3852 \\
\hline $\mathrm{R}^{2}$ & 0.101 & 0.102 & 0.011 \\
\hline
\end{tabular}

Fonte: Ministério da Educação. Censos Escolares 2000 e 2006; IBGE. Censo Demográfico 2000.

(1) $\mathrm{p}<0.1$.

(2) $\mathrm{p}<0.01$.

(3) $\mathrm{p}<0.05$.

Nota: Desvios-padrões robustos em parênteses. 
A Tabela 5 mostra o impacto do programa sobre o ganho de Ideb na $4^{\text {a }}$ série das escolas entre 2005 e 2007, evidenciando que este efeito tende a se tornar mais negativo com o tempo. Uma explicação vem da piora em aprovação nas escolas tratadas, uma vez que o Ideb é função da aprovação e das notas na Prova Brasil. As duas próximas tabelas revelam ter havido incremento pequeno entre 2005 e 2007 na Prova Brasil para alunos da $4^{\mathrm{a}}$ série, o que permite concluir que a piora no Ideb está relacionada com aprovação.

As Tabelas 6 e 7 evidenciam os efeitos do programa sobre desempenho na Prova Brasil da 4a série em 2005 e nos ganhos entre 2005 e 2007, respectivamente. Os resultados assemelham-se às Tabelas 4 e 5, com exceção de que o impacto do programa foi maior em 2005 do que em 2007. De fato, embora o ganho positivo não seja significativo do ponto de vista estatístico, os resultados apontam que talvez haja incrementos de aprendizado de longo prazo relacionados à introdução de tecnologias de informação junto a crianças do ensino fundamental I.

Tabela 6

Impacto sobre desempenho na Prova Brasil na $4^{\text {a }}$ série 2005

\begin{tabular}{l|r|r|r}
\hline & MQO & $\begin{array}{r}\text { MQO com } \\
\text { interação }\end{array}$ & P-score \\
\hline Tratamento & $\begin{array}{r}-0.209^{(2)} \\
(0.034)\end{array}$ & $\begin{array}{r}-0.207^{(2)} \\
(0.035)\end{array}$ & $\begin{array}{r}-0.264^{(2)} \\
(0.029)\end{array}$ \\
\hline Tratamento(1) (No comput. / aluno E.F.) & & -5.201 & \\
\hline Tratamento(1) Internet & & -0.065 & \\
\hline No de salas de aula & & $(0.363)$ & \\
\hline No de turmas no ensino fundamental & $0.018^{(2)}$ & $0.018^{(2)}$ & \\
\hline Internet & $(0.003)$ & $(0.003)$ & \\
\hline$N^{\circ}$ comput. / alunos ens. fundamental & $(0.002)$ & $(0.002)$ & \\
\hline$N^{\circ}$ de professores do E. F. & -0.146 & -0.144 & \\
\hline & $(0.089)$ & $(0.090)$ & \\
\hline & $-0.004^{(2)}$ & $-0.004^{(2)}$ & \\
\hline & $(0.001)$ & $(0.001)$ & \\
\hline
\end{tabular}


Tabela 6

Impacto sobre desempenho na Prova Brasil na $4^{\text {a }}$ série 2005

\begin{tabular}{l|r|r|r}
\hline \multirow{2}{*}{ Propensity score } & MQO & $\begin{array}{c}\text { MQO com } \\
\text { interação }\end{array}$ & P-score \\
\hline \multirow{2}{*}{ Constante } & & & $0.570^{(2)}$ \\
\cline { 2 - 4 } & & & $(0.159)$ \\
\hline$N$ & $4.182^{(2)}$ & $4.182^{(2)}$ & $4.342^{(2)}$ \\
\cline { 2 - 4 } & $(0.025)$ & $(0.025)$ & $(0.015)$ \\
\hline$R^{2}$ & 3252 & 3252 & 3252 \\
\hline
\end{tabular}

Fonte: Ministério da Educação. Censos Escolares 2000 e 2006; IBGE. Censo Demográfico 2000.

(1) $\mathrm{p}<0.1$.

(2) $\mathrm{p}<0.01$.

Nota: Desvios-padrōes robustos em parênteses.

Tabela 7

Impacto sobre desempenho na Prova Brasil na 4ª série 2007

\begin{tabular}{l|c|c|c}
\hline & MQO & $\begin{array}{c}\text { MQO com } \\
\text { interação }\end{array}$ & P-score \\
\hline Tratamento & $\begin{array}{c}-0.191^{(2)} \\
(0.036)\end{array}$ & $\begin{array}{r}-0.189^{(2)} \\
(0.037)\end{array}$ & $\begin{array}{r}-0.231^{(2)} \\
(0.039)\end{array}$ \\
\hline Tratamento(1) $\mathrm{N}^{\circ}$ comput. / aluno E.F.) & & 0.309 & \\
\hline Tratamento(1) Internet & & -15.08 & \\
\hline No de salas de aula & & -0.145 & \\
\hline No de turmas no ensino fundamental & -0.002 & -0.239 & \\
\hline Internet & -0.002 & -0.002 & \\
\hline \multirow{2}{*}{ No comput. / alunos ens. fundamental } & $22.865^{(2)}$ & $22.872^{(2)}$ & \\
\hline No de professores do E. F. & -6.31 & -6.377 & \\
\hline
\end{tabular}


Tabela 7

Impacto sobre desempenho na Prova Brasil na $4^{\mathrm{a}}$ série 2007

\begin{tabular}{l|r|r|r}
\hline & MQO & $\begin{array}{c}\text { MQO com } \\
\text { interação }\end{array}$ & P-score \\
\hline \multirow{2}{*}{ Propensity score } & & & $0.604^{(2)}$ \\
\cline { 2 - 4 } & & & -0.144 \\
\hline \multirow{2}{*}{ Constante } & $4.307^{(2)}$ & $4.307^{(2)}$ & $4.443^{(2)}$ \\
\cline { 2 - 4 } $\mathrm{N}$ & -0.022 & -0.022 & -0.013 \\
\hline $\mathrm{R}^{2}$ & 3852 & 3852 & 3852 \\
\hline
\end{tabular}

Fonte: Ministério da Educação. Censos Escolares 2000 e 2006; IBGE. Censo Demográfico 2000.

(1) $\mathrm{p}<0.1$.

(2) $\mathrm{p}<0.01$.

Nota: Desvios-padrôes robustos em parênteses.

Já as Tabelas 8 a 11 relatam os impactos do programa sobre proficiência em português e matemática para a $4^{\mathrm{a}}$ série em 2005 e para os ganhos entre 2005 e 2007. Os resultados mostram que para todos os casos o impacto do programa no curto prazo foi negativo pelos três métodos de estimação utilizados. Porém, ao se comparar 2005 com 2007, os resultados tendem a ficar menos negativos, ainda que não se possa rejeitar a hipótese nula de que o ganho temporal tenha sido zero. De todo modo, os resultados negativos tendem a estar em conformidade com evidências prévias existentes na literatura brasileira e internacional.

\section{Tabela 8}

Impacto sobre proficiência em Português na $4^{\text {a }}$ série 2005

\begin{tabular}{l|r|r|r}
\hline & MQO & $\begin{array}{r}\text { MQO com } \\
\text { interação }\end{array}$ & \multicolumn{1}{|c}{ P-score } \\
\hline Tratamento & $\begin{array}{r}-5.623^{(2)} \\
(1.000)\end{array}$ & $\begin{array}{r}-5.510^{(2)} \\
(1.019)\end{array}$ & $\begin{array}{r}-7.069^{(2)} \\
(1.046)\end{array}$ \\
\hline Tratamento(1) (No comput. / aluno E.F.) & & $\begin{array}{r}-328.569 \\
(519.495)\end{array}$ & \\
\hline Tratamento(1) Internet & & $\begin{array}{r}3.466 \\
(10.834)\end{array}$ & \\
\hline No de salas de aula & & $0.487^{(2)}$ & \\
\hline No de turmas no ensino fundamental & $0.487^{(2)}$ & $(0.088)$ & \\
\hline
\end{tabular}


Tabela 8

Impacto sobre proficiência em Português na $4^{a}$ série 2005

\begin{tabular}{l|r|r|r}
\hline & \multicolumn{1}{|c|}{ MQO } & $\begin{array}{r}\text { MQO com } \\
\text { interação }\end{array}$ & P-score \\
\hline Internet & $\begin{array}{r}-4.243^{(1)} \\
(2.434)\end{array}$ & $\begin{array}{r}-4.228^{(1)} \\
(2.450)\end{array}$ & \\
\hline \multirow{2}{*}{ N comput. / alunos ens. fundamental $^{\circ}$} & $\begin{array}{r}1,131.736^{(2)} \\
(173.765)\end{array}$ & $\begin{array}{r}1,135.777^{(2)} \\
(176.732)\end{array}$ & \\
\hline No de professores do E. F. & $-0.117^{(2)}$ & $-0.118^{(2)}$ & \\
\hline Propensity score & $(0.031)$ & $(0.031)$ & \\
\hline Constante & & & $18.627^{(2)}$ \\
\hline $\mathrm{N}$ & $162.738^{(2)}$ & $162.734^{(2)}$ & $167.261^{(2)}$ \\
\hline $\mathrm{R}^{2}$ & $(0.679)$ & $(0.679)$ & $(0.470)$ \\
\hline
\end{tabular}

Fonte: Ministério da Educação. Censos Escolares 2000 e 2006; IBGE. Censo Demográfico 2000.

(1) $\mathrm{p}<0.1$.

(2) $\mathrm{p}<0.01$.

Nota: Desvios-padrôes robustos em parênteses.

Tabela 9

Impacto sobre proficiência em Português na 4a série 2007

\begin{tabular}{l|r|r|r}
\hline & MQO & $\begin{array}{r}\text { MQO com } \\
\text { interação }\end{array}$ & P-score \\
\hline Tratamento & $\begin{array}{r}-4.920^{(2)} \\
(0.985)\end{array}$ & $\begin{array}{r}-4.907^{(2)} \\
(1.010)\end{array}$ & $\begin{array}{r}-5.925^{(2)} \\
(0.823)\end{array}$ \\
\hline Tratamento $^{(1)}\left(\mathrm{N}^{\circ}\right.$ comput. / aluno E.F.) & & $\begin{array}{r}84.386 \\
(386.273)\end{array}$ & \\
\hline Tratamento $^{(1)}$ Internet & & -5.137 & \\
\hline No de salas de aula & & $(7.025)$ & \\
\hline No de turmas no ensino fundamental & $0.574^{(2)}$ & $0.574^{(2)}$ & \\
& $(0.082)$ & $(0.082)$ & \\
\hline Internet & -0.037 & -0.038 & \\
\hline
\end{tabular}


Tabela 9

Impacto sobre proficiência em Português na $4^{\text {a }}$ série 2007

\begin{tabular}{l|r|r|r}
\hline & MQO & $\begin{array}{r}\text { MQO com } \\
\text { interação }\end{array}$ & P-score \\
\hline $\begin{array}{l}N^{\circ} \text { comput. / alunos ens. } \\
\text { fundamental }\end{array}$ & $\begin{array}{r}623.258^{(2)} \\
(165.426)\end{array}$ & $\begin{array}{r}622.745^{(2)} \\
(167.030)\end{array}$ & \\
\hline$N^{\circ}$ de professores do E. F. & $-0.104^{(2)}$ & $-0.104^{(2)}$ & \\
\hline Propensity score & $(0.030)$ & $(0.030)$ & \\
\hline Constante & & & $17.442^{(2)}$ \\
\hline $\mathrm{N}$ & $161.927^{(2)}$ & $161.928^{(2)}$ & $\begin{array}{r}165.398^{(2)} \\
(0.338)\end{array}$ \\
\hline $\mathrm{R}^{2}$ & $(0.594)$ & $(0.594)$ & 3852 \\
\hline \hline
\end{tabular}

Fonte: Ministério da Educação. Censos Escolares 2000 e 2006; IBGE. Censo Demográfico 2000.

(1) $\mathrm{p}<0.1$.

(2) $\mathrm{p}<0.01$.

Nota: Desvios-padrōes robustos em parênteses.

Tabela 10

Impacto sobre proficiência em Matemática na $4^{\text {a }}$ série 2005

\begin{tabular}{|c|c|c|c|}
\hline & MQO & $\begin{array}{l}\text { MQO com } \\
\text { interação }\end{array}$ & P-score \\
\hline \multirow{2}{*}{ Tratamento } & $-5.602^{(2)}$ & $-5.580^{(2)}$ & $-7.098^{(2)}$ \\
\hline & $(0.915)$ & $(0.927)$ & $(0.829)$ \\
\hline \multirow{2}{*}{ Tratamento ${ }^{(1)}$ ( ${ }^{\circ}$ comput. / aluno E.F.) } & & 46.779 & \\
\hline & & $(438.247)$ & \\
\hline \multirow{2}{*}{ Tratamento(1) Internet } & & -6.745 & \\
\hline & & $(9.137)$ & \\
\hline \multirow{2}{*}{$N^{\circ}$ de salas de aula } & $0.501^{(2)}$ & $0.500^{(2)}$ & \\
\hline & $(0.091)$ & $(0.091)$ & \\
\hline \multirow{2}{*}{$N^{\circ}$ de turmas no ensino fundamental } & -0.021 & -0.021 & \\
\hline & $(0.047)$ & $(0.047)$ & \\
\hline \multirow{2}{*}{ Internet } & -3.585 & -3.523 & \\
\hline & $(2.412)$ & $(2.428)$ & \\
\hline
\end{tabular}


Tabela 10

Impacto sobre proficiência em Matemática na $4^{\text {a }}$ série 2005

\begin{tabular}{l|r|r|r}
\hline & MQO & \multicolumn{1}{|c|}{$\begin{array}{c}\text { MQO com } \\
\text { interação }\end{array}$} & P-score \\
\hline$N^{\circ}$ comput. / alunos ens. fundamental & $\begin{array}{r}1,081.346^{(2)} \\
(164.170)\end{array}$ & $\begin{array}{r}1,082.836^{(2)} \\
(166.655)\end{array}$ & \\
\hline$N^{\circ}$ de professores do E. F. & $\begin{array}{r}-0.098^{(2)} \\
(0.031)\end{array}$ & $\begin{array}{r}-0.098^{(2)} \\
(0.031)\end{array}$ & \\
\hline Propensity score & & & $\begin{array}{r}12.065^{(2)} \\
(3.212)\end{array}$ \\
\hline Constante & $170.758^{(2)}$ & $170.757^{(2)}$ & $\begin{array}{r}174.875^{(2)} \\
(0.382)\end{array}$ \\
\hline $\mathrm{N}$ & $(0.675)$ & $(0.675)$ & 3252 \\
\hline $\mathrm{R}^{2}$ & 3252 & 3252 & 0.010 \\
\hline
\end{tabular}

Fonte: Ministério da Educação. Censos Escolares 2000 e 2006; IBGE. Censo Demográfico 2000.

(1) $\mathrm{p}<0.1$.

(2) $\mathrm{p}<0.01$.

Nota: Desvios-padrôes robustos em parênteses.

Tabela 11

Impacto sobre proficiência em Matemática na $4^{a}$ série 2007

\begin{tabular}{l|r|r|r}
\hline & MQO & $\begin{array}{c}\text { MQO com } \\
\text { interação }\end{array}$ & P-score \\
\hline Tratamento & $-5.298^{(2)}$ & $-5.249^{(2)}$ & $-6.475^{(2)}$ \\
& $(1.028)$ & $(1.055)$ & $(1.071)$ \\
\hline Tratamento(1) (No comput. / aluno E.F.) & & -57.415 & \\
\hline Tratamento(1) Internet & & $(426.950)$ & \\
\hline \multirow{2}{*}{ No de salas de aula } & & -2.664 & \\
\hline \multirow{2}{*}{ No de turmas no ensino fundamental } & $-0.634^{(2)}$ & $0.634^{(2)}$ & \\
\hline Internet & $(0.090)$ & $(0.090)$ & \\
\hline
\end{tabular}


Tabela 11

Impacto sobre proficiência em Matemática na $4^{\text {a }}$ série 2007

\begin{tabular}{l|r|r|r}
\hline & \multicolumn{1}{|c|}{ MQO } & \multicolumn{1}{c|}{$\begin{array}{c}\text { MQO com } \\
\text { interação }\end{array}$} & P-score \\
\hline$N^{\circ}$ comput. / alunos ens. fundamental & $\begin{array}{r}604.556^{(2)} \\
(173.658)\end{array}$ & $\begin{array}{r}605.352^{(2)} \\
(175.667)\end{array}$ & \\
\hline $\mathrm{N}^{\circ}$ de professores do E. F. & $-0.080^{(3)}$ & $-0.080^{(3)}$ & \\
\hline Propensity score & $(0.033)$ & $(0.033)$ & \\
\hline Constante & & & $14.989^{(2)}$ \\
\hline $\mathrm{N}$ & $178.110^{(2)}$ & $178.110^{(2)}$ & $181.892^{(2)}$ \\
$\mathrm{R}^{2}$ & $(0.633)$ & $(0.634)$ & $(0.399)$ \\
\hline
\end{tabular}

Fonte: Ministério da Educação. Censos Escolares 2000 e 2006; IBGE. Censo Demográfico 2000.

(1) $\mathrm{p}<0.1$.

(2) $\mathrm{p}<0.01$.

(3) $\mathrm{p}<0.05$.

Nota: Desvios-padrōes robustos em parênteses.

Nas Tabelas A.1 a A.9 do apêndice A repetiu-se o mesmo procedimento, mas para alunos da $8^{\mathrm{a}}$ série. Assim como para a $4^{\mathrm{a}}$ série, os efeitos de curto prazo são negativos, contudo, tendem a perdurar por mais tempo e nenhuma evidencia de reversão é encontrada. Tal resultado nos leva a concluir que a introdução de tecnologias de informação nas escolas não parece afetar de maneira positiva alunos mais velhos.

\section{3 - Resultados para variáveis de recursos das escolas}

A Tabela 12 mostra que os resultados sobre escolaridade média dos professores, existência de laboratório e acesso à infraestrutura pelo método das diferenças em diferençassão bastante distintos. A hipótese levantada de que a participação no programa poderia atrair professores mais qualificados para a escola não se verificou, uma vez que este não impacta a escolaridade média dos docentes. 
Tabela 12

Impacto sobre recursos escolares usando diferenças em diferenças

\begin{tabular}{|c|c|c|c|c|}
\hline & $\begin{array}{l}\text { Escolaridade } \\
\text { média dos } \\
\text { professores }\end{array}$ & Estrutura 1 & Estrutura 2 & Laboratório \\
\hline Tratamento ${ }^{(1)}$ tempo & $\begin{array}{l}-0.119 \\
(0.079) \\
\end{array}$ & $\begin{array}{l}-0.013^{(2)} \\
(0.003) \\
\end{array}$ & $\begin{array}{l}-0.076^{(2)} \\
(0.014) \\
\end{array}$ & $\begin{array}{l}0.575^{(2)} \\
(0.029) \\
\end{array}$ \\
\hline Tempo & $\begin{array}{l}0.623^{(2)} \\
(0.056) \\
\end{array}$ & $\begin{array}{l}0.060^{(2)} \\
(0.002) \\
\end{array}$ & $\begin{array}{l}0.410^{(2)} \\
(0.008) \\
\end{array}$ & $\begin{array}{l}-0.061^{(2)} \\
(0.013) \\
\end{array}$ \\
\hline $\mathrm{N}^{\circ}$ de salas ${ }^{(1)}$ tempo & $\begin{array}{l}0.015 \\
(0.009)\end{array}$ & $\begin{array}{l}-0.001^{(2)} \\
(0.000)\end{array}$ & $\begin{array}{l}-0.004^{(1)} \\
(0.002)\end{array}$ & $\begin{array}{l}-0.002 \\
(0.002) \\
\end{array}$ \\
\hline $\mathrm{N}^{\circ}$ de turmas ${ }^{(1)}$ tempo & $\begin{array}{l}-0.012^{(3)} \\
(0.005)\end{array}$ & $\begin{array}{l}-0.002^{(2)} \\
(0.000)\end{array}$ & $\begin{array}{l}-0.008^{(2)} \\
(0.001) \\
\end{array}$ & $\begin{array}{l}0.004^{(2)} \\
(0.001)\end{array}$ \\
\hline Internet ${ }^{(1)}$ tempo & $\begin{array}{l}0.331^{(2)} \\
(0.125) \\
\end{array}$ & $\begin{array}{l}0.020^{(2)} \\
(0.003) \\
\end{array}$ & $\begin{array}{l}0.108^{(2)} \\
(0.029) \\
\end{array}$ & $\begin{array}{l}-0.335^{(2)} \\
(0.039) \\
\end{array}$ \\
\hline $\begin{array}{l}\left(N^{\circ} \text { comput. / aluno }\right. \\
\text { E.F. })^{(1)} \text { tempo }\end{array}$ & $\begin{array}{c}-23.555^{(2)} \\
(6.813) \\
\end{array}$ & $\begin{array}{l}-0.620^{(2)} \\
(0.101) \\
\end{array}$ & $\begin{array}{l}-4.486^{(2)} \\
(0.966) \\
\end{array}$ & $\begin{array}{l}-3.921^{(3)} \\
(1.882) \\
\end{array}$ \\
\hline $\begin{array}{l}\text { № de prof. E. F. }{ }^{(1)} \\
\text { tempo }\end{array}$ & $\begin{array}{l}-0.012^{(2)} \\
(0.002) \\
\end{array}$ & $\begin{array}{l}-0.001^{(2)} \\
(0.000) \\
\end{array}$ & $\begin{array}{l}-0.005^{(2)} \\
(0.000) \\
\end{array}$ & $\begin{array}{l}0.005^{(2)} \\
(0.001)\end{array}$ \\
\hline Tempo & $\begin{array}{l}0.553^{(2)} \\
(0.048) \\
\end{array}$ & $\begin{array}{l}0.011^{(2)} \\
(0.001) \\
\end{array}$ & $\begin{array}{l}0.110^{(2)} \\
(0.012) \\
\end{array}$ & $\begin{array}{l}-0.051^{(2)} \\
(0.017) \\
\end{array}$ \\
\hline$N^{\circ}$ de salas de aula & $\begin{array}{l}0.043^{(2)} \\
(0.008)\end{array}$ & $\begin{array}{l}0.001^{(2)} \\
(0.000)\end{array}$ & $\begin{array}{l}0.013^{(2)} \\
(0.002)\end{array}$ & $\begin{array}{l}0.012^{(2)} \\
(0.001)\end{array}$ \\
\hline $\begin{array}{l}\text { No de turmas no } \\
\text { ensino fundamental }\end{array}$ & $\begin{array}{l}0.040^{(2)} \\
(0.004) \\
\end{array}$ & $\begin{array}{l}0.002^{(2)} \\
(0.000) \\
\end{array}$ & $\begin{array}{l}0.013^{(2)} \\
(0.001) \\
\end{array}$ & $\begin{array}{l}0.007^{(2)} \\
(0.001) \\
\end{array}$ \\
\hline Internet & $\begin{array}{c}-0.530^{(2)} \\
(0.117) \\
\end{array}$ & $\begin{array}{l}-0.021^{(2)} \\
(0.003) \\
\end{array}$ & $\begin{array}{c}-0.188^{(2)} \\
(0.029)\end{array}$ & $\begin{array}{l}0.371^{(2)} \\
(0.037) \\
\end{array}$ \\
\hline $\begin{array}{l}N^{\circ} \text { comput. / alunos } \\
\text { Ens. Fundamental }\end{array}$ & $\begin{array}{l}31.944^{(2)} \\
(6.656)\end{array}$ & $\begin{array}{l}0.632^{(2)} \\
(0.101) \\
\end{array}$ & $\begin{array}{l}5.518^{(2)} \\
(0.958)\end{array}$ & $\begin{array}{l}11.125^{(2)} \\
(1.703)\end{array}$ \\
\hline $\begin{array}{l}N^{0} \text { de professores do } \\
\text { E. F. }\end{array}$ & $\begin{array}{l}0.013^{(2)} \\
(0.002) \\
\end{array}$ & $\begin{array}{l}0.001^{(2)} \\
(0.000) \\
\end{array}$ & $\begin{array}{l}0.006^{(2)} \\
(0.000) \\
\end{array}$ & $\begin{array}{l}-0.006^{(2)} \\
(0.000)\end{array}$ \\
\hline Constante & $\begin{array}{l}10.934^{(2)} \\
(0.028)\end{array}$ & $\begin{array}{l}0.938^{(2)} \\
(0.002)\end{array}$ & $\begin{array}{l}0.393^{(2)} \\
(0.006)\end{array}$ & $\begin{array}{l}-0.005^{(1)} \\
(0.002)\end{array}$ \\
\hline $\mathrm{N}$ & 27693 & 31344 & 31344 & 31344 \\
\hline $\mathrm{R}^{2}$ & 0.140 & 0.034 & 0.260 & 0.456 \\
\hline
\end{tabular}

Fonte: Ministério da Educação. Censos Escolares 2000 e 2006; IBGE. Censo Demográfico 2000.

(1) $\mathrm{p}<0.1$; 2) $\mathrm{p}<0.01 ;(3) \mathrm{p}<0.05$.

Nota: Desvios-padrōes robustos em parênteses. 
Os resultados mostraram que o impacto do programa sobre a estrutura da escola (medida pela variável "Estrutura 1" como acesso à água, ou esgoto, ou energia elétrica e pela variável “Estrutura 2" como acesso à água, esgoto e energia elétrica) é negativo, o que pode ser fruto dos altos valores previamente existentes dessas variáveis nas escolas tratadas.

Outro resultado averiguado foram os efeitos sobre a existência de laboratório de informática ou ciências, onde se evidenciou que a participação no programa aumentou na média em 57,5 pontos percentuais a probabilidade de ter laboratório. Tal fato mostra que o programa ampliou sensivelmente o acesso dos alunos a laboratórios, muito mais do que teriam se não participassem do programa.

\section{Conclusões}

O presente trabalho oferece algumas evidências à literatura ao respeito do impacto das tecnologias de informação e comunicação sobre as escolas. Avaliou-se aqui um programa que distribuiu equipamentos de informática e treinou os professores para que esses fossem utilizados corretamente. Para avaliar o impacto do programa, valeu-se de um estimador de diferenças em diferenças e de métodos de seleção em observáveis, utilizando um grupo de controle gerado a partir de escolas pertencentes a municípios na mesma UF e com IDH semelhante ao dos municípios das escolas tratadas no programa.

Em geral, obteve-se que o impacto do programa no curto prazo foi estatisticamente significativo e negativo sobre diversas medidas de qualidade da educação tanto para 2005 quanto para 2007. Tal resultado corrobora as evidências previamente encontradas na literatura, como por exemplo, Dwyer et al. (2007) para o Brasil e Angrist e Lavy (2002) para Israel. A explicação oferecida por Angrist e Lavy (2002) para o resultado de Israel de que o uso das tecnologias de informação e comunicação diminui o tempo de sala de aula talvez não se aplique às escolas pertencentes às regiōes brasileiras com IDH mais baixo. Contudo, faltam evidências para testar esse mecanismo.

Os resultados encontrados apontam ainda que a despeito de o impacto do programa no curto prazo ter sido negativo sobre desempenho dos alunos da $4^{\mathrm{a}}$ e $8^{\mathrm{a}}$ séries do ensino fundamental, para alunos da $4^{\mathrm{a}}$ série, esse resultado negativo fica menor em termos absolutos ao longo do tempo, indicando que parece haver um efeito de longo prazo positivo, porém pequeno, entre crianças mais novas e expostas às novas tecnologias de informação. Tal resultado não é encontrado para a $8^{\mathrm{a}}$ série, 
onde se constatam resultados de longo prazo nulos ou negativos, indicando que crianças mais velhas, quando expostas a tecnologias de informação nas escolas, não apresentam ganhos de aprendizado.

Evidenciou-se também impacto positivo sobre o acesso à Internet e que o programa promoveu um sensível aumento da existência de laboratórios de informática e ciência nas escolas, algo que possivelmente sem ele não ocorreria. Esses ganhos não são diretamente medidos pela Prova Brasil, a qual avalia conhecimento em Matemática e Língua Portuguesa. Portanto, pode ter havido outros ganhos do programa não mensurados na análise aqui efetuada.

De fato, vale enfatizar que este estudo não pretende captar todos os potenciais impactos do programa, uma vez que é impossível observar todas as variáveis de resposta sobre as quais ele pode ter tido efeito. É importante, contudo, ressaltar que, conforme evidência da literatura internacional, para que políticas que aumentem a oferta de recursos tecnológicos no ensino surtam efeito, elas devem ser combinadas com mudanças no uso de tais insumos e com treinamento específico e eficaz de professores para utilização de novas tecnologias.

\section{Referências bibliográficas}

ANGRIST, J. D.; LAVY, V. New Evidence on Classroom Computers and Pupil Learning. Economic Journal, 112, pp. 735-765, 2002.

ANGRIST, J. D.; PISCHKE, J. Mostly Harmless Econometrics: Na Empiricist's Companion. Princeton University Press, 2008.

BARRERA-OSORIO, F; LINDEN, L. L. The Use and Misuse of Computers in Education: Evidence from a Randomized Controlled Trial of a Language Arts Program. Working paper, março de 2009.

BARROS, A. C. et al. Uso de computadores no Ensino Fundamental e Médio e seus resultados empíricos: uma revisão sistemática da literatura. Revista Brasileira de Informática na Educação, v. 16, n. 1, 2008.

CURI, A. ; MENEZES FILHO, N. A. . A Relação entre Educação Pré-primária, Salários, Escolaridade e Proficiência Escolar no Brasil. Estudos Econômicos (USP. Impresso), v. 39, p. 811-850, 2009.

DWYER et al. Desvendando mitos: os computadores e o desempenho no sistema escolar. Educação e Sociedade, vol. 28, n. 101, Campinas, 2007. 
HANUSHEK, Eric A. \& KIMKO, D, "Schooling, Labor-Force Quality, and the Growth of Nations," American Economic Review, American Economic Association, vol. 90(5), pages 1184-1208, December, 2000.

INEP - Instituto Nacional de Estudos e Pesquisas Educacionais Anísio Teixeira. Disponível em: <www. inep.gov.br>. Acesso em: 27 ago. 2011.

KIST, S. O.; SCHÄFER, P. B.; BITTENCOURT, J.; FAGUNDES, L. C. Impacto da modalidade 1:1 nas práticas de leitura e escrita: primeiros resultado. Simpósio Brasileiro de Informática na Educação, 2007.

KOZMA, R., MCGHEE, R., QUELLMALZ, E. and ZALLES, D. Closing the digital divide: Evaluation of the World Links program. International Journal of Educational Development, 24(4), pp. 361-381, 2004.

LINDEN, L., BANERJEE, A.; DUFLO, E. Computer-Assisted Learning: Evidence from a Randomized Experiment. Poverty Action Lab Paper No. 5, outubro de 2003.

LINDEN, L. Complement or Substitute? The Effect of Technology on Student Achievement in India," mimeo Columbia University, 2008.

NERI, M.; MOURA, R.; CORREA, M. Infra-estrutura e avanços educacionais. Fundação Getúlio Vargas. Disponível em: <http://www4.fgv.br/cps/simulador/site_cps_educacao/ WB_relatoriofinal.pdf>. Acesso em: setembro de 2011.

OCDE - Organização para Cooperação e Desenvolvimento Econômico. Disponível em: www.oecd.org. Acesso em: dezembro de 2010.

OI TONOMUNDO. Disponível em: <www.tonomundo.org.br> Acessado em: dezembro de 2010 .

ROUSE, C. E.; KRUEGER, A. B. Putting computerized instruction to the test: a randomized evaluation of a 'scientifically based' reading program. Journal Economics of Education Review, 23(4), pp. 323-338, 2004.

WENGLINSKY, H. Does it compute? The relationship between educational technology and student achievement in mathematics. Princeton, NJ: ETS, 1998. 


\section{Apêndice A}

Aqui são apresentadas as tabelas A.1 a A.10, que correspondem aos efeitos do programa sobre todas as variáveis de desempenho dos alunos explicitadas na seção 4.2, mas para a $8^{a}$ série. Como se pode observar, os resultados são muito semelhantes no sentido de que a participação no programa tem impacto negativo sobre o desempenho dos alunos.

Tabela A1

Impacto sobre a taxa de aprovação na $8^{\mathrm{a}}$ série 2005

\begin{tabular}{|c|c|c|c|}
\hline & MQO & $\begin{array}{l}\text { MQO com } \\
\text { interação }\end{array}$ & P-score \\
\hline Tratamento & $\begin{array}{c}-0.066^{(2)} \\
(0.009)\end{array}$ & $\begin{array}{c}-0.064^{(2)} \\
(0.009)\end{array}$ & $\begin{array}{c}-0.062^{(2} \\
(0.009)\end{array}$ \\
\hline Tratamento(1) ( $n^{\circ}$ comput. / aluno E.F.) & & $\begin{array}{c}3.040 \\
(1.909)\end{array}$ & \\
\hline Tratamento $^{(1)}$ Internet & & $\begin{array}{c}-0.184^{(2)} \\
(0.055)\end{array}$ & \\
\hline$N^{\circ}$ de salas de aula & $\begin{array}{c}-0.003^{(2)} \\
(0.001)\end{array}$ & $\begin{array}{c}-0.003^{(2)} \\
(0.001)\end{array}$ & \\
\hline$N^{\circ}$ de turmas no ensino fundamental & $\begin{array}{c}0.000 \\
(0.000)\end{array}$ & $\begin{array}{c}0.000 \\
(0.000)\end{array}$ & \\
\hline Internet & $\begin{array}{l}0.040^{(2)} \\
(0.013)\end{array}$ & $\begin{array}{l}0.048^{(2)} \\
(0.013)\end{array}$ & \\
\hline$N^{\circ}$ comput. / alunos ens. fundamental & $\begin{array}{l}2.164^{(2)} \\
(0.474)\end{array}$ & $\begin{array}{l}2.135^{(2)} \\
(0.509)\end{array}$ & \\
\hline No de professores do E. F. & $\begin{array}{c}-0.001^{(2)} \\
(0.000)\end{array}$ & $\begin{array}{c}-0.001^{(2)} \\
(0.000)\end{array}$ & \\
\hline Propensity score & & & $\begin{array}{c}-0.102^{(2} \\
(0.031)\end{array}$ \\
\hline Constante & $\begin{array}{l}0.731^{(2)} \\
(0.007)\end{array}$ & $\begin{array}{l}0.731^{(2)} \\
(0.007)\end{array}$ & $\begin{array}{l}0.708^{(2)} \\
(0.004)\end{array}$ \\
\hline $\mathrm{N}$ & 2361 & 2361 & 2361 \\
\hline $\mathrm{R}^{2}$ & 0.058 & 0.061 & 0.024 \\
\hline
\end{tabular}

Fonte: Ministério da Educação. Censos Escolares 2000 e 2006; IBGE. Censo Demográfico 2000.

(1) $\mathrm{p}<0.1$.

(2) $\mathrm{p}<0.01$.

Nota: Desvios-padrôes robustos em parênteses. 
Tabela A2

Impacto sobre o Ideb na $8^{\text {a }}$ série 2005

\begin{tabular}{|c|c|c|c|}
\hline & MQO & $\begin{array}{l}\text { MQO com } \\
\text { interação }\end{array}$ & P-score \\
\hline \multirow{2}{*}{ Tratamento } & $-0.435^{(2)}$ & $-0.407^{(2)}$ & $-0.424^{(2)}$ \\
\hline & $(0.046)$ & $(0.047)$ & $(0.044)$ \\
\hline \multirow{2}{*}{ Tratamento ${ }^{(1)}\left(\mathrm{N}^{\circ}\right.$ comput. / aluno E.F.) } & & 4.024 & \\
\hline & & $(12.758)$ & \\
\hline \multirow{2}{*}{ Tratamento(1) Internet } & & $-0.812^{(2)}$ & \\
\hline & & $(0.305)$ & \\
\hline \multirow{2}{*}{$N^{\circ}$ de salas de aula } & 0.001 & 0.001 & \\
\hline & $(0.004)$ & $(0.004)$ & \\
\hline \multirow{2}{*}{$\mathrm{N}^{\circ}$ de turmas no ensino fundamental } & 0.001 & 0.001 & \\
\hline & $(0.002)$ & $(0.002)$ & \\
\hline \multirow{2}{*}{ Internet } & $0.234^{(3)}$ & $0.289^{(2)}$ & \\
\hline & $(0.092)$ & $(0.097)$ & \\
\hline \multirow{2}{*}{$N^{\circ}$ comput. / alunos ens. fundamental } & $22.055^{(2)}$ & $23.026^{(2)}$ & \\
\hline & $(3.631)$ & $(3.972)$ & \\
\hline \multirow{2}{*}{$\mathrm{N}^{\circ}$ de professores do $\mathrm{E} . \mathrm{F}$. } & $-0.006^{(2)}$ & $-0.006^{(2)}$ & \\
\hline & $(0.001)$ & $(0.001)$ & \\
\hline \multirow{2}{*}{ Propensity score } & & & $-0.450^{(2)}$ \\
\hline & & & $(0.144)$ \\
\hline \multirow{2}{*}{ Constante } & $2.980^{(2)}$ & $2.979^{(2)}$ & $3.014^{(2)}$ \\
\hline & $(0.039)$ & $(0.039)$ & $(0.022)$ \\
\hline $\mathrm{N}$ & 2361 & 2361 & 2361 \\
\hline $\mathrm{R}^{2}$ & 0.098 & 0.101 & 0.030 \\
\hline
\end{tabular}

Fonte: Ministério da Educação. Censos Escolares 2000 e 2006; IBGE. Censo Demográfico 2000.

(1) $\mathrm{p}<0.1$.

(2) $\mathrm{p}<0.01$.

(3) $\mathrm{p}<0.05$.

Nota: Desvios-padrōes robustos em parênteses. 
Tabela A3

Impacto sobre o Ideb na $8^{\text {a }}$ série 2007

\begin{tabular}{|c|c|c|c|}
\hline & MQO & $\begin{array}{l}\text { MQO com } \\
\text { interação }\end{array}$ & P-score \\
\hline \multirow{2}{*}{ Tratamento } & $-0.576^{(2)}$ & $-0.544^{(2)}$ & $-0.582^{(2)}$ \\
\hline & $(0.044)$ & $(0.044)$ & $(0.041)$ \\
\hline \multirow{2}{*}{ 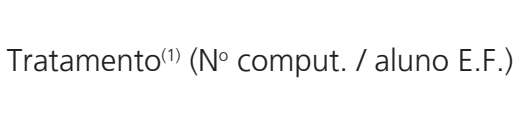 } & & -0.046 & \\
\hline & & $(12.231)$ & \\
\hline \multirow{2}{*}{ Tratamento(1) Internet } & & $-0.880^{(2)}$ & \\
\hline & & $(0.307)$ & \\
\hline \multirow{2}{*}{$N^{\circ}$ de salas de aula } & 0.001 & 0.001 & \\
\hline & $(0.004)$ & $(0.004)$ & \\
\hline \multirow{2}{*}{$\mathrm{N}^{\circ}$ de turmas no ensino fundamental } & 0.001 & 0.001 & \\
\hline & $(0.002)$ & $(0.002)$ & \\
\hline \multirow{2}{*}{ Internet } & $0.433^{(2)}$ & $0.493^{(2)}$ & \\
\hline & $(0.095)$ & $(0.097)$ & \\
\hline \multirow{2}{*}{$N^{\circ}$ comput. / alunos ens. fundamental } & $22.434^{(2)}$ & $23.364^{(2)}$ & \\
\hline & $(3.408)$ & $(3.596)$ & \\
\hline \multirow{2}{*}{$N^{\circ}$ de professores do E. F. } & $-0.006^{(2)}$ & $-0.006^{(2)}$ & \\
\hline & $(0.001)$ & $(0.001)$ & \\
\hline \multirow{2}{*}{ Propensity score } & & & -0.338 \\
\hline & & & $(0.208)$ \\
\hline \multirow{2}{*}{ Constante } & $3.163^{(2)}$ & $3.163^{(2)}$ & $3.212^{(2)}$ \\
\hline & $(0.038)$ & $(0.038)$ & $(0.025)$ \\
\hline $\mathrm{N}$ & 2778 & 2778 & 2778 \\
\hline $\mathrm{R}^{2}$ & 0.117 & 0.120 & 0.040 \\
\hline
\end{tabular}

Fonte: Ministério da Educação. Censos Escolares 2000 e 2006; IBGE. Censo Demográfico 2000.

(1) $\mathrm{p}<0.1$.

(2) $\mathrm{p}<0.01$

Nota: Desvios-padrôes robustos em parênteses. 
Tabela A4

Impacto sobre desempenho na Prova Brasil na $8^{\text {a }}$ série 2005

\begin{tabular}{|c|c|c|c|}
\hline & MQO & $\begin{array}{l}\text { MQO com } \\
\text { interação }\end{array}$ & P-score \\
\hline \multirow{2}{*}{ Tratamento } & $-0.245^{(2)}$ & $-0.226^{(2)}$ & $-0.253^{(2)}$ \\
\hline & $(0.029)$ & $(0.030)$ & $(0.025)$ \\
\hline \multirow{2}{*}{ Tratamento ${ }^{(1)}\left(\mathrm{N}^{\circ}\right.$ comput. / aluno E.F.) } & & -10.062 & \\
\hline & & $(7.076)$ & \\
\hline \multirow{2}{*}{ Tratamento(1) Internet } & & -0.020 & \\
\hline & & $(0.177)$ & \\
\hline \multirow{2}{*}{$N^{\circ}$ de salas de aula } & $0.017^{(2)}$ & $0.017^{(2)}$ & \\
\hline & $(0.003)$ & $(0.003)$ & \\
\hline \multirow{2}{*}{$\mathrm{N}^{\circ}$ de turmas no ensino fundamental } & -0.001 & -0.001 & \\
\hline & $(0.002)$ & $(0.002)$ & \\
\hline \multirow{2}{*}{ Internet } & 0.079 & 0.101 & \\
\hline & $(0.065)$ & $(0.069)$ & \\
\hline \multirow{2}{*}{$N^{\circ}$ comput. / alunos ens. fundamental } & $15.718^{(2)}$ & $16.931^{(2)}$ & \\
\hline & $(2.643)$ & $(2.866)$ & \\
\hline \multirow{2}{*}{$\mathrm{N}^{\circ}$ de professores do E. F. } & $-0.005^{(2)}$ & $-0.005^{(2)}$ & \\
\hline & $(0.001)$ & $(0.001)$ & \\
\hline \multirow{2}{*}{ Propensity score } & & & -0.034 \\
\hline & & & $(0.110)$ \\
\hline \multirow{2}{*}{ Constante } & $4.064^{(2)}$ & $4.063^{(2)}$ & $4.230^{(2)}$ \\
\hline & $(0.029)$ & $(0.029)$ & $(0.015)$ \\
\hline N & 2361 & 2361 & 2361 \\
\hline $\mathrm{R}^{2}$ & 0.126 & 0.128 & 0.019 \\
\hline
\end{tabular}

Fonte: Ministério da Educação. Censos Escolares 2000 e 2006; IBGE. Censo Demográfico 2000.

(1) $\mathrm{p}<0.1$.

(2) $\mathrm{p}<0.01$.

Nota: Desvios-padrōes robustos em parênteses. 
Tabela A5

Impacto sobre desempenho na Prova Brasil na $8^{\text {a }}$ série 2007

\begin{tabular}{|c|c|c|c|}
\hline & MQO & $\begin{array}{l}\text { MQO com } \\
\text { interação }\end{array}$ & P-score \\
\hline \multirow{2}{*}{ Tratamento } & $-0.250^{(2)}$ & $-0.234^{(2)}$ & $-0.266^{(2)}$ \\
\hline & $(0.026)$ & $(0.026)$ & $(0.028)$ \\
\hline \multirow{2}{*}{ Tratamento(1) (No comput. / aluno E.F.) } & & -9.100 & \\
\hline & & $(6.417)$ & \\
\hline \multirow{2}{*}{ Tratamento(1) Internet } & & -0.027 & \\
\hline & & $(0.180)$ & \\
\hline \multirow{2}{*}{$N^{\circ}$ de salas de aula } & $0.017^{(2)}$ & $0.017^{(2)}$ & \\
\hline & $(0.003)$ & $(0.003)$ & \\
\hline \multirow{2}{*}{ № de turmas no ensino fundamental } & -0.001 & -0.001 & \\
\hline & $(0.002)$ & $(0.002)$ & \\
\hline \multirow{2}{*}{ Internet } & $0.117^{(1)}$ & $0.135^{(1)}$ & \\
\hline & $(0.066)$ & $(0.069)$ & \\
\hline \multirow{2}{*}{ No comput. / alunos ens. fundamental } & $19.450^{(2)}$ & $20.190^{(2)}$ & \\
\hline & $(2.513)$ & $(2.686)$ & \\
\hline \multirow{2}{*}{$N^{0}$ de professores do E. F. } & $-0.005^{(2)}$ & $-0.005^{(2)}$ & \\
\hline & $(0.001)$ & $(0.001)$ & \\
\hline \multirow{2}{*}{ Propensity score } & & & 0.139 \\
\hline & & & $(0.125)$ \\
\hline \multirow{2}{*}{ Constante } & $4.069^{(2)}$ & $4.069^{(2)}$ & $4.228^{(2)}$ \\
\hline & $(0.027)$ & $(0.027)$ & $(0.015)$ \\
\hline $\mathrm{N}$ & 2778 & 2778 & 2778 \\
\hline R2 & 0.165 & 0.167 & 0.018 \\
\hline
\end{tabular}

Fonte: Ministério da Educação. Censos Escolares 2000 e 2006; IBGE. Censo Demográfico 2000.

(1) $\mathrm{p}<0.1$.

(2) $\mathrm{p}<0.01$.

Nota: Desvios-padrões robustos em parênteses. 
Tabela A6

Impacto sobre proficiência em Português na $8^{\text {a }}$ série 2005

\begin{tabular}{|c|c|c|c|}
\hline & MQO & $\begin{array}{l}\text { MQO com } \\
\text { interação }\end{array}$ & P-score \\
\hline \multirow{2}{*}{ Tratamento } & $-6.711^{(2)}$ & $-6.258^{(2)}$ & $-6.951^{(2)}$ \\
\hline & $(0.873)$ & $(0.891)$ & $(0.780)$ \\
\hline \multirow{2}{*}{ 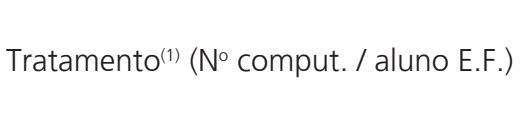 } & & -304.448 & \\
\hline & & $(204.313)$ & \\
\hline \multirow{2}{*}{ Tratamento(1) Internet } & & 2.837 & \\
\hline & & $(5.439)$ & \\
\hline \multirow{2}{*}{$N^{\circ}$ de salas de aula } & $0.537^{(2)}$ & $0.534^{(2)}$ & \\
\hline & $(0.084)$ & $(0.084)$ & \\
\hline \multirow{2}{*}{$N^{\circ}$ de turmas no ensino fundamental } & -0.045 & -0.047 & \\
\hline & $(0.046)$ & $(0.046)$ & \\
\hline \multirow{2}{*}{ Internet } & 2.313 & 2.702 & \\
\hline & $(1.798)$ & $(1.904)$ & \\
\hline \multirow{2}{*}{ № comput. / alunos ens. fundamental } & $410.719^{(2)}$ & $441.283^{(2)}$ & \\
\hline & & & \\
\hline \multirow{2}{*}{$N^{\circ}$ de professores do E. F. } & $-0.141^{(2)}$ & $-0.140^{(2)}$ & \\
\hline & $(0.028)$ & $(0.028)$ & \\
\hline \multirow{2}{*}{ Propensity score } & & & 0.144 \\
\hline & & & $(3.392)$ \\
\hline \multirow{2}{*}{ Constante } & $215.185^{(2)}$ & $215.162^{(2)}$ & $220.114^{(2)}$ \\
\hline & $(0.859)$ & $(0.861)$ & $(0.562)$ \\
\hline $\mathrm{N}$ & 2361 & 2361 & 2361 \\
\hline $\mathrm{R}^{2}$ & 0.117 & 0.119 & 0.017 \\
\hline
\end{tabular}

Fonte: Ministério da Educação. Censos Escolares 2000 e 2006; IBGE. Censo Demográfico 2000.

(1) $\mathrm{p}<0.1$.

(2) $\mathrm{p}<0.01$.

Nota: Desvios-padróes robustos em parênteses. 
Tabela A7

Impacto sobre proficiência em Português na $8^{\mathrm{a}}$ série 2007

\begin{tabular}{|c|c|c|c|}
\hline & MQO & $\begin{array}{l}\text { MQO com } \\
\text { interação }\end{array}$ & P-score \\
\hline \multirow{2}{*}{ Tratamento } & $-7.315^{(2)}$ & $-6.961^{(2)}$ & $-7.765^{(2)}$ \\
\hline & $(0.796)$ & $(0.815)$ & $(0.834)$ \\
\hline \multirow{2}{*}{ Tratamento(1) ( $\mathrm{N}^{\circ}$ comput. / aluno E.F.) } & & -226.396 & \\
\hline & & (192.419) & \\
\hline \multirow{2}{*}{ Tratamento(1) Internet } & & 0.802 & \\
\hline & & $(5.610)$ & \\
\hline \multirow{2}{*}{$N^{\circ}$ de salas de aula } & $0.514^{(2)}$ & $0.512^{(2)}$ & \\
\hline & $(0.088)$ & $(0.088)$ & \\
\hline \multirow{2}{*}{$N^{\circ}$ de turmas no ensino fundamental } & 0.003 & 0.001 & \\
\hline & $(0.050)$ & $(0.050)$ & \\
\hline \multirow{2}{*}{ Internet } & $3.574^{(1)}$ & $3.910^{(3)}$ & \\
\hline & $(1.843)$ & $(1.931)$ & \\
\hline \multirow{2}{*}{$N^{\circ}$ comput. / alunos ens. fundamental } & $528.465^{(2)}$ & $545.302^{(2)}$ & \\
\hline & $(66.598)$ & $(70.748)$ & \\
\hline \multirow{2}{*}{$N^{\circ}$ de professores do E. F. } & $-0.153^{(2)}$ & $-0.153^{(2)}$ & \\
\hline & $(0.027)$ & $(0.027)$ & \\
\hline \multirow{2}{*}{ Propensity score } & & & $7.251^{(3)}$ \\
\hline & & & (3.672) \\
\hline \multirow{2}{*}{ Constante } & $216.746^{(2)}$ & $216.749^{(2)}$ & $221.878^{(2}$ \\
\hline & $(0.832)$ & $(0.833)$ & $(0.465)$ \\
\hline $\mathrm{N}$ & 2778 & 2778 & 2778 \\
\hline$R^{2}$ & 0.146 & 0.147 & 0.017 \\
\hline
\end{tabular}

Fonte: Ministério da Educação. Censos Escolares 2000 e 2006; IBGE. Censo Demográfico 2000.

(1) $\mathrm{p}<0.1$.

(2) $\mathrm{p}<0.01$.

(3) $\mathrm{p}<0.05$.

Nota: Desvios-padrōes robustos em parênteses. 
Tabela A8

Impacto sobre proficiência em Matemática na $8^{\text {a }}$ série 2005

\begin{tabular}{|c|c|c|c|}
\hline & MQO & $\begin{array}{l}\text { MQO com } \\
\text { interação }\end{array}$ & P-score \\
\hline \multirow{2}{*}{ Tratamento } & $-8.003^{(2)}$ & $-7.264^{(2)}$ & $-8.207^{(2)}$ \\
\hline & $(0.937)$ & $(0.960)$ & $(0.985)$ \\
\hline \multirow{2}{*}{ Tratamento ${ }^{(1)}\left(\mathrm{N}^{\circ}\right.$ comput. / aluno E.F.) } & & -297.900 & \\
\hline & & $(223.094)$ & \\
\hline \multirow{2}{*}{ Tratamento(1) Internet } & & -4.103 & \\
\hline & & $(5.381)$ & \\
\hline \multirow{2}{*}{$N^{\circ}$ de salas de aula } & $0.479^{(2)}$ & $0.477^{(2)}$ & \\
\hline & $(0.091)$ & $(0.091)$ & \\
\hline \multirow{2}{*}{$\mathrm{N}^{\circ}$ de turmas no ensino fundamental } & -0.022 & -0.026 & \\
\hline & $(0.052)$ & $(0.052)$ & \\
\hline \multirow{2}{*}{ Internet } & 2.423 & 3.339 & \\
\hline & $(2.168)$ & $(2.315)$ & \\
\hline \multirow{2}{*}{ № comput. / alunos ens. fundamental } & $532.375^{(2)}$ & $574.500^{(2)}$ & \\
\hline & $(90.311)$ & $(99.284)$ & \\
\hline \multirow{2}{*}{$\mathrm{N}^{\circ}$ de professores do E. F. } & $-0.149^{(2)}$ & $-0.148^{(2)}$ & \\
\hline & $(0.031)$ & $(0.031)$ & \\
\hline \multirow{2}{*}{ Propensity score } & & & -2.139 \\
\hline & & & $(3.931)$ \\
\hline \multirow{2}{*}{ Constante } & $228.665^{(2)}$ & $228.629^{(2)}$ & $233.690^{(2)}$ \\
\hline & $(0.916)$ & $(0.918)$ & $(0.460)$ \\
\hline $\mathrm{N}$ & 2361 & 2361 & 2361 \\
\hline $\mathrm{R}^{2}$ & 0.125 & 0.127 & 0.020 \\
\hline
\end{tabular}

Fonte: Ministério da Educação. Censos Escolares 2000 e 2006; IBGE. Censo Demográfico 2000.

(1) $\mathrm{p}<0.1$.

(2) $\mathrm{p}<0.01$.

Nota: Desvios-padrōes robustos em parênteses. 
Tabela A9

Impacto sobre proficiência em Matemática na $8^{\text {a }}$ série 2007

\begin{tabular}{|c|c|c|c|}
\hline & MQO & $\begin{array}{l}\text { MQO com } \\
\text { interação }\end{array}$ & P-score \\
\hline \multirow{2}{*}{ Tratamento } & $-7.701^{(2)}$ & $-7.069^{(2)}$ & $-8.238^{(2)}$ \\
\hline & $(0.826)$ & $(0.841)$ & $(0.993)$ \\
\hline \multirow{2}{*}{ Tratamento $^{(1)}$ ( $\mathrm{N}^{\circ}$ comput. / aluno E.F.) } & & -320.876 & \\
\hline & & $(198.600)$ & \\
\hline \multirow{2}{*}{ Tratamento(1) Internet } & & -2.385 & \\
\hline & & $(5.468)$ & \\
\hline \multirow{2}{*}{$\mathrm{N}^{\circ}$ de salas de aula } & $0.519^{(2)}$ & $0.516^{(2)}$ & \\
\hline & $(0.099)$ & $(0.099)$ & \\
\hline \multirow{2}{*}{$N^{\circ}$ de turmas no ensino fundamental } & -0.064 & -0.068 & \\
\hline & $(0.052)$ & $(0.053)$ & \\
\hline \multirow{2}{*}{ Internet } & 3.496 & $4.215^{(1)}$ & \\
\hline & $(2.189)$ & $(2.309)$ & \\
\hline \multirow{2}{*}{ No comput. / alunos ens. fundamental } & $638.911^{(2)}$ & $666.484^{(2)}$ & \\
\hline & $(87.039)$ & $(93.354)$ & \\
\hline \multirow{2}{*}{ No de professores do E. F. } & $-0.152^{(2)}$ & $-0.151^{(2)}$ & \\
\hline & $(0.029)$ & $(0.029)$ & \\
\hline \multirow{2}{*}{ Propensity score } & & & 1.112 \\
\hline & & & $(4.197)$ \\
\hline \multirow{2}{*}{ Constante } & $227.376^{(2)}$ & $227.382^{(2)}$ & $231.825^{(2)}$ \\
\hline & $(0.867)$ & $(0.867)$ & $(0.537)$ \\
\hline N & 2778 & 2778 & 2778 \\
\hline $\mathrm{R}^{2}$ & 0.170 & 0.172 & 0.017 \\
\hline
\end{tabular}

Fonte: Ministério da Educação. Censos Escolares 2000 e 2006; IBGE. Censo Demográfico 2000.

(1) $\mathrm{p}<0.1$.

(2) $\mathrm{p}<0.01$.

Nota: Desvios-padrões robustos em parênteses. 


\section{Apêndice B}

$\mathrm{Na}$ tabela B.1 está a estimação da probabilidade de ser tratado de acordo com as características da escola e do município (Propensity score). Tal estimação serviu de base para as regressões que usaram o propensity score como variável explicativa.

\section{Tabela B.1}

Coeficientes do Propensity-Score estimado por regressão logística

\begin{tabular}{l|c}
\hline No de salas de aula & -0.014 \\
\hline No de turmas no ensino fundamental & $(0.013)$ \\
\hline Internet & $0.107^{(1)}$ \\
\hline No comput. / alunos ens. fundamental & $0.007)$ \\
\hline No de professores do E. F. & -0.434 \\
\hline Constante & $(0.371)$ \\
\hline$N$ & -4.714 \\
\hline$R^{2}$ & $(14.188)$ \\
\hline
\end{tabular}

Fonte: Ministério da Educação. Censos Escolares 2000 e 2006; IBGE. Censo Demográfico 2000.

(1) $\mathrm{p}<0.01$.

Nota: Desvios-padrões robustos em parênteses.

ENDEREÇO PARA CORRESPONDÊCIA:

Sergio Firpo - sergio.firpo@fgv.br

R. Itapeva, 474/1215

São Paulo, SP 01332-000

Brasil

Renan Gomes De Pieri - renan.pieri@gvmail.br

R. Itapeva, 474/1215

São Paulo, SP 01332-000

Brasil 
